\title{
SOBRE PLURALISMO, VERDADE E TOLERÂNCIA: DIÁLOGOS EPISTEMOLÓGICOS E ÉTICOS PARA UMA EDUCAÇÃO INTERCULTURAL
}

\author{
MARCELO ANDRADE*
}

\begin{abstract}
RESUMO: Multiculturalismo e interculturalidade, ainda que guardem distinções, são conceitos que têm conquistado grande espaço no discurso educacional. Há uma série de pesquisas que os aproximam do campo do currículo, da prática pedagógica e da educação popular. Este trabalho, por sua vez, visa a contribuir com o debate no campo dos fundamentos da educação. Nesse sentido, o objetivo foi eleger duas abordagens teóricas e trazê-las para o diálogo sobre questões epistemológicas e éticas, a fim de ressignificar o debate sobre a perspectiva intercultural em educação, privilegiando os conceitos de verdade, pluralismo e tolerância. Assim, foi privilegiado o diálogo com Karl Popper e Noberto Bobbio. Com o primeiro, buscou-se entender como a concepção de verdade pode ajudar a entender uma proposta de educação intercultural. Com o segundo, buscou-se avançar das questões epistemológicas para os desafios éticos sobre o pluralismo e a tolerância na prática pedagógica.
\end{abstract}

Palavras-chave: Educação intercultural. Tolerância. Karl Popper. Norberto Bobbio

\section{ON PLURALISM, TOLERANCE AND TRUTH: EPISTEMOLOGICAL AND} ETHICAL DIALOG FOR INTERCULTURAL EDUCATION

\begin{abstract}
Although very different from one another, the concepts of multiculturalism and interculturality have grown in importance in the educational discourse. Several studies have brought such concepts closer to the curriculum field, the pedagogical practice and popular education. To contribute to the debate on the foundations of education, this work focuses on two theoretical approaches regarding ethical and epistemological issues. This is intended to reframe the intercultural perspective, in education, with an emphasis on the concepts of truth, pluralism and tolerance through a dialogue between Karl Popper and Norberto Bobbio. Based on the former, this paper shows how the concept of truth can help us understand a proposal for intercultural education, while the latter allows it to advance from epistemological issues to some of the ethical challenges faced by pluralism and tolerance in the pedagogical practice.
\end{abstract}

Key words: Intercultural education. Tolerance. Karl Popper. Norberto Bobbio.

Doutor em Ciências Humanas e professor do Programa de Pós-Graduação em Educação da Pontifícia Universidade Católica do Rio de Janeiro (PUC-Rio). E-mail: marcelo-andrade@puc-rio.br 
SUR Le PLURALISME, LA VÉRITÉ ET LA TOLÉRANCE: DIALOGUES ÉPISTÉMOLOGIQUES ET ÉTHIQUES POUR UNE ÉDUCATION INTERCULTURELLE

RÉSUMÉ: Malgré leurs différences, les concepts de multiculturalisme et d'interculturalité prennent de plus en plus d'importance dans le discours éducationnel. Toute une série de recherches les rapprochent du champ des programmes scolaires, de la pratique pédagogique et de l'éducation populaire. Comme travail cherche à contribuer au débat sur les fondements de l'éducation, il a choisi deux approches théoriques pour les introduire dans le dialogue sur les questions épistémologiques et éthiques et recadrer la perspective interculturelle en éducation en privilégiant les concepts de vérité, de pluralisme et de tolérance. Ainsi le dialogue avec Karl Popper et Norberto Bobbio a-t-il été privilégié. En effet, le premier nous permet de comprendre comment la conception de vérité peut aider à saisir une proposition d'éducation interculturelle, alors que le second nous fait passer des questions épistémologiques aux défis éthiques sur le pluralisme et la tolérance dans la pratique pédagogique.

Mots-clés: Éducation interculturelle. Tolérance. Karl Popper. Norberto Bobbio.

onceitos como multiculturalismo, educação intercultural, diversidade cultural, pluralismo religioso, direito à diferença e às identidades de gênero, de raça, de orientação sexual, de pertencimento ou de geração têm conquistado grande espaço no discurso educacional nas últimas décadas. No contexto brasileiro, pesquisadores consagrados no campo, como Tomaz Tadeu da Silva (2000a; 2000b), Vera Maria Candau (2002; 2006; 2008), Antônio Flávio Moreira (1999; 2002), Reinaldo Fleury (2003; 2006), entre outros, têm buscado as relações entre esses conceitos e os seus campos de pesquisa, tais como: currículo, prática pedagógica e educação popular. Os suportes teóricos privilegiados nas pesquisas vão desde autores considerados pós-modernos, como Focault e Derrida, a autores consagrados no campo da educação progressista, como Freire e McLaren. No âmbito da filosofia da educação, são poucas as pesquisas que abortam diretamente o tema da diferença. No entanto, neste campo, a temática da tolerância epistemológica e ética parece que tem sido central para se repensar os fundamentos da educação, como mostram os trabalhos de Roseli Fischmann $(2001 ; 2007$; 2008) e Clodoaldo Cardoso (2003). Este trabalho pretende contribuir nesta perspectiva.

Afinal, quais as contribuições que uma abordagem ético-filosófica da educação pode apresentar sobre as temáticas da diversidade cultural na prática pedagógica? Não tenho ambição de responder exaustivamente tal questão. Meu objetivo aqui é eleger dois teóricos ainda pouco explorados no campo e trazê-los para o diálogo sobre as questões epistemológicas (centradas no conceito de verdade) e éticas (centradas nos conceitos de pluralismo e de tolerância), a fim de ressignificar o debate sobre a perspectiva intercultural em educação. Minha escolha foi baseada, 
principalmente, na fecundidade da obra dos autores e, também, na falta que os mesmos fazem em qualquer diálogo que queira ser, ao mesmo tempo, contemporâneo e cauteloso, acerca dos velhos - e falaciosos - dilemas sobre particular e universal, diferença e igualdade, subjetividade e objetividade, contingência e necessidade. Assim, neste artigo, pretendo articular as abordagens teóricas de Karl Popper e Noberto Bobbio. Com o primeiro, tratarei de entender como a concepção de verdade pode nos ajudar a fundamentar uma proposta de educação intercultural. Com o segundo, pretendo avançar das questões epistemológicas para os desafios éticos e políticos sobre o pluralismo e a tolerância na prática pedagógica.

\section{Popper: certeza indefinida ou incerteza definida?}

Karl Popper é um dos mais importantes filósofos da ciência do século xx. Sua obra é extensa e bastante complexa. Para os propósitos deste trabalho, a sua principal contribuição será a noção de falseabilidade como critério fundamental para a demarcação das teorias científicas, apresentada principalmente na obra A lógica da pesquisa científica (1972).

Para Popper (1972, p. 41), "todo conhecimento é conjetural", sendo impossível o estabelecimento de uma certeza definitiva. Essa impossibilidade deve-se ao fato de todo conhecimento possuir intrinsecamente uma falseabilidade, ou seja, toda hipótese científica traz em si a possibilidade da refutação, a probabilidade do erro. E é por isso que a ciência se corrige, progride e se aproxima cada vez mais da verdade. Nesse sentido, para Popper (op. cit., p. 53), nenhuma teoria científica possui toda a verdade. A ciência realiza um movimento de aproximação à verdade, mas toda e qualquer teoria científica opera e se constrói a partir da impossibilidade de conter uma verdade definitiva. É preciso frisar, no entanto, que Popper não defende a impossibilidade da verdade, mas tão somente a falta de garantias para que ela se estabeleça definitivamente.

A contribuição de Popper para se pensar a relação da verdade com os conceitos de pluralismo e tolerância vem da relação, ou da transposição, de suas considerações do âmbito da filosofia da ciência para o âmbito da ética. Em A sociedade aberta e seus inimigos (1987a), fica mais clara a relação entre lógica e ética em seu pensamento. Ele relaciona princípios científicos e morais através de seu conceito de demarcação entre a ciência e a pseudociência (Popper, 1972). Para Popper, uma teoria é científica sempre que é falível e refutável. Se não há possibilidade de uma teoria ser refutável, o mais provável é que não seja científica. Será, de fato, uma doutrina dogmática.

Segundo Artigas (1998, p. 15), o preço que uma teoria deve pagar para entrar no âmbito do conhecimento científico é a atitude que a leve a "procurar contra- 
exemplos que possam mostrar seus erros ou refutar suas certezas provisórias". A atitude de sempre considerar a possibilidade do erro, a falseabilidade, é o que garante ao conhecimento científico avançar. A relação entre verificação e falsificação é a chave do método científico popperiano, que consiste em uma procura intensa pelo erro, já que nunca se poderia demonstrar com certeza absoluta que as teorias são definitivamente verdadeiras. Segundo Popper (1972), a busca por contra-exemplos seria o único caminho para que uma teoria possa se aproximar da verdade e postular a cientificidade.

A aplicação dessas ideias no âmbito da ética tem a sociedade aberta como resultado. Se, tal como entende Popper, o conhecimento é essencialmente falível e refutável, então, deveríamos cultivar a disposição para retificar nossas ideias e as examinar criticamente. A sociedade aberta está baseada na possibilidade da crítica, na rejeição de qualquer tipo de autoritarismo e de dogmatismo e, sobretudo, na tolerância (Popper, 1987a). Em A sociedade aberta e seus inimigos, ele expõe sua teoria social, enfrentando o contexto mundial marcado à época pelo totalitarismo, em suas versões nazista, fascista e socialista.

A conexão entre epistemologia e ética parecem claras e lineares no pensamento popperiano. Para Popper (1972; 1987a), filosofia da ciência e filosofia moral (ou ética) são duas faces da mesma moeda. Se na ciência empírica nunca se pode demonstrar de um modo conclusivo a verdade, este princípio também se aplica às teorias metafísicas sobre a moralidade, que tampouco poderiam ser demonstradas como verdades definitivas. Dessa forma, elas também devem ser submetidas à mesma crítica racional que as demais teorias. A utilização de argumentos racionais para as ciências sociais e humanas - ainda que não possuam a força típica dos experimentos científicos empíricos - seria o suficiente para submetê-las a um processo de eliminação do erro, análogo ao das ciências empíricas.

Popper (1987b) apresenta uma interessante síntese de sua teoria da falseabilidade científica e metafísica a partir de três princípios básicos: (1) Eu posso estar errado e você pode ter razão; (2) Conversando racionalmente sobre as coisas, talvez possamos corrigir alguns de nossos enganos; (3) Conversando racionalmente sobre as coisas, talvez possamos ficar mais próximos à verdade.

Numa conferência intitulada The Knowledge of the Ignorance, por ocasião do recebimento do título de Doutor Honoris Causa na Universidad Complutense de Madrid, Popper (1994, p. 78) retoma seus três princípios e declara:

Es extraordinario que esos tres principios sean epistemológicos y, al mismo tiempo, sean también principios éticos. Porque implican, entre otras cosas, tolerancia: si yo puedo aprender de usted, y si yo quiero aprender en el interés por la búsqueda de la verdad, no sólo debo tolerarle como persona, sino que debo reconocerle potencialmente como a un igual. El principio ético que nos guíe deberá ser nuestro compromiso con la búsqueda 
de la verdad y la noción de una vía para llegar a la verdad y un acercamiento a ella. Sobre todo, deberíamos entender que nunca podremos estar seguros de haber llegado a la verdad; que tenemos que seguir haciendo críticas, autocríticas, de lo que creemos haber encontrado y, por consiguiente, tenemos que seguir poniéndolo a prueba con espíritu crítico; que tenemos que esforzarnos mucho en la crítica y que nunca deberíamos llegar a ser complacientes y dogmáticos. Y también debemos vigilar constantemente nuestra integridad intelectual, que junto con el conocimiento de nuestra falibilidad nos llevará a una actitud de autocrítica y de tolerancia.

A tolerância como uma postura, ao mesmo tempo, epistemológica e ética inclui o crivo para a responsabilidade intelectual (Popper, 1987b). A tolerância é fruto de um processo e de uma aposta que nasce desses três princípios: a falibilidade $\left(1^{\circ}\right)$, o diálogo racional $\left(2^{\circ}\right)$ e a aproximação da verdade pelo debate $\left(3^{\circ}\right)$.

Os princípios da falseabilidade popperiana nascem da convicção socrática sobre a relação dos humanos com o conhecimento. Por ocasião da conferência na Complutense de Madrid, Popper (1994) afirmou que a máxima socrática "só sei que nada sei" deveria ser a bússola de todo cientista e intelectual em seu movimento de aproximação à verdade. O cientista deve reconhecer que, de fato, não sabe, mas supõe. A quase totalidade dos conhecimentos científicos é mera suposição. O cientista deve também admitir que a ignorância é infinita e uma realidade maior que todo e qualquer esforço humano pelo conhecimento. O cientista deve reconhecer que, hoje, ainda mais do que no tempo de Sócrates, é impossível dominar todos os conhecimentos acumulados pela humanidade.

Em Toleration and intellectual responsibility, Popper (1987b) define também duas posturas éticas distintas para o cientista ou intelectual diante da verdade: uma postura antiga e o que ele chama de "nova postura". A postura antiga está baseada na crença de que é possível obter um conhecimento correto, do qual se deriva a autoridade científica ou acadêmica atribuída ao intelectual ou cientista. A nova postura deveria admitir que o conhecimento é incerto e, por isso, objetivamente desautorizado, no sentido de não conceder uma autoridade absoluta ao cientista. Segundo Plastino (2001), vivemos em tempos de incerteza diante dos fracassos do paradigma moderno. Sem dúvidas, Popper foi um dos primeiros epistemólogos que trabalhou a favor da não absolutização e da incerteza desse paradigma.

Assim, considero Popper "o filósofo da impossibilidade da verdade definitiva" e, com ele, encontramos uma série de recomendações para a responsabilidade intelectual e científica, a saber: não há autoridades pré-estabelecidas nas áreas do saber; nem sempre é possível evitar o erro, ainda que devamos fazer todo o possível para evitá-lo; os erros devem ser incessantemente buscados e revelados e nunca ocultados, pois aprendemos com os nossos erros e com os dos outros; devemos cultivar uma autocrítica franca, aceitar com generosidade as críticas alheias e apresentar aos outros as nossas críticas de maneira objetiva e benevolente (Popper, 1987b). 
Para Popper (1987b), a melhor crítica é a autocrítica, pois esta busca os próprios erros, aprende com eles e os demonstra aos outros. É preciso reconhecer que, além da autocrítica, necessitamos também das críticas alheias. Necessitamos uns dos outros para a correção dos erros e para o avanço da verdade. É, nesta perspectiva, que a comunidade científica ganha seu valor, pois ela não é apenas uma aglomeração de notáveis, mas sim uma resposta à necessária reciprocidade científica e intelectual. A correção recíproca de erros e enganos, entre cientistas e intelectuais, é algo que deveria ser entendido como uma realidade intrínseca à nossa condição mental, enquanto seres inteligentes e intersubjetivos. Assim, para Popper, o reconhecimento de tal reciprocidade e a apresentação da crítica objetiva e benevolente aos demais são as condições para um estado de tolerância para consigo mesmo e para com os outros. Para Artigas (1998), a crítica objetiva e benevolente é composta de objeções ou concordâncias que não são dirigidas à pessoa do cientista e nem se baseiam em condições subjetivas, tais como inimizade ou amizade, simpatia ou antipatia. A crítica objetiva está direcionada às ideias em debate e é motivada pela busca da verdade. No entanto, deve ser benevolente, isto é, apresentada com generosidade, sem intenção de atingir o sujeito, mas sim os seus argumentos.

Popper sublinhou o caráter conjetural do conhecimento humano e a impossibilidade de adquirir demonstrações conclusivas, propondo um pensamento claramente antidogmático, no qual não há lugar para a certeza definitiva e indubitável, contrariando claramente o ideal cartesiano. Contudo, segundo Artigas (1998, p. 32), o "racionalismo crítico popperiano" fundou-se em uma "fé irracional na razão", fruto de uma "decisão moral" a favor do racionalismo. De acordo com Antigas (op. cit.), a atitude de levar a sério os argumentos racionais não pode ser fundamentada por meios racionais e, por esse motivo, Popper afirmava que, em última instância, seu racionalismo crítico estava baseado em uma decisão moral irracional. No entanto, a fé irracional no racionalismo crítico de Popper não é uma doutrina, mas uma atitude. Ele não propõe um sistema filosófico irracional, mas uma atitude que considera importante, por razões éticas, e não plenamente explicável pela razão. Trata-se da atitude de diálogo e de razoabilidade que favorece a tolerância e a compreensão do pluralismo frente a qualquer tipo de totalitarismo ou etnocentrismo.

Popper (1994, p. 255) admite explicitamente que sua posição científica está baseada em um compromisso de tipo ético e ela só faz sentido à luz do conceito de tolerância:

Así, los principios éticos constituyen la base de la ciencia. La idea de verdad como principio regulador fundamental - el principio que guía nuestra búsqueda - puede considerarse un principio ético. La búsqueda de la verdad y la idea de aproximación a la verdad también son principios éticos; como lo son las ideas de integridad intelectual y falibilidad, que nos conducen a una actitud de autocrítica y de tolerancia. 
A análise das raízes éticas do conceito epistemológico de verdade, no pensamento popperiano, interessa-me aqui para a defesa do pluralismo e da tolerância. Também é interessante mostrar que os três princípios da falseabilidade - falibilidade, diálogo racional e aproximação à verdade - são, ao mesmo tempo, princípios epistemológicos e éticos. Esta declaração seria bastante para mostrar que a falseabilidade não se refere apenas a um assunto meramente lógico, mas que lógica (científica) e ética (filosófica) se entrelaçam e se retroalimentam.

Ainda que de maneira preliminar, arriscaria dizer que a suposição básica da filosofia de Popper está numa aposta no ser humano e em sua capacidade de ser livre (capaz de fazer escolhas), racionável (capaz de dar explicações plausíveis), plural (diverso, múltiplo) e tolerante (aberto às diferenças). Popper está fortemente comprometido com essas concepções sobre o ser humano, e todos os seus argumentos os supõem. Tais concepções são fundamentais para uma educação intercultural, como tentarei indicar adiante.

\section{Bobbio: pluralismo, verdade e serenidade}

O cientista político Norberto Bobbio conquistou um lugar de destaque entre os pensadores contemporâneos. Para o diálogo sobre pluralismo, verdade e tolerância é fundamental considerar sua obra Elogio da serenidade e outros escritos morais (2002).

Importa começar reconhecendo, com Bobbio (2002, p. 19), que o tema da tolerância pode se referir a dois problemas diferentes:

\footnotetext{
Uma coisa é o problema da tolerância de crenças ou opiniões diversas, que exige uma reflexão sobre a compatibilidade teórica e, sobretudo, prática entre verdades contrapostas; outra coisa é o problema da tolerância diante daquele que é diverso por razões físicas ou sociais, que põe em primeiro plano o tema do preconceito e da consequente discriminação. As razões que se podem apresentar em defesa da tolerância no primeiro significado não são as mesmas que se apresentam para defendê-la no segundo. Em decorrência, são distintas as razões das duas formas de intolerância. A primeira deriva da convicção de possuir a verdade; a segunda se fecunda geralmente num preconceito.
}

A intolerância que se baseia na crença da verdade absoluta é, em geral, de caráter religioso ou político. Neste caso, uma proposta de tolerância como respeito ao pluralismo tem como desafio responder à seguinte questão: “Como podem ser teórica e praticamente compatíveis duas verdades contrapostas?". Já a intolerância que se baseia em preconceitos tem como característica atentar contra a diversidade humana e se constitui em forma de racismo, sexismo, homofobia, xenofobia etc. Neste caso, uma proposta de tolerância deve responder a outro desafio: “Como se pode demonstrar que certas impaciências com respeito a uma minoria de pessoas diversas 
derivam de preconceitos inveterados, de formas irracionais, puramente emotivas, de julgar homens e eventos?". No primeiro caso, a tolerância e o pluralismo buscam combater o absolutismo das verdades indubitáveis, ao passo que, no segundo, busca combater o preconceito e a discriminação. Tal como Popper, Bobbio desafia-se a duas tarefas distintas e interligadas, uma epistemológica e outra ética.

\section{Tolerância e verdade}

Quanto à busca de compatibilidade entre verdades contrapostas, Bobbio (2002) faz uma distinção na maneira de se entender a verdade, separando monistas de pluralistas. Os primeiros são os que acreditam que só há uma concepção de verdade e, dentre eles, distinguem-se quatro posturas. A primeira está baseada na crença de que a verdade é expansiva, ou seja, ela se estende sobre os erros. Assim, as doutrinas alheias são erros que, cedo ou tarde, dissipar-se-ão. O conhecimento estaria em franco processo de expansão e a humanidade, por sua vez, progrediria necessariamente para formas mais completas de entendimento da verdade. Aqui, a tolerância é totalmente passiva diante do pluralismo. Trata-se de uma atitude de espera, isto é, de que os outros percebam seus erros. Tolerar é deixar que as doutrinas errôneas caminhem em direção à verdade (Walzer, 1999).

A segunda postura também acredita que a verdade avançará sobre o erro, mas não como algo determinado (idem, ibid.). Não existe aqui um otimismo, mas o reconhecimento da necessidade de empenho na difusão da verdade. A verdade só superará o erro à custa de muito trabalho. Assim, a tolerância é a opção pelo recurso da persuasão racional para se fazer avançar a verdade e a recusa do uso da força para a eliminação dos erros alheios. Tolerar seria aguentar, como favor de condescendência, os limites alheios.

A terceira postura se estabelece por razões utilitárias (idem, ibid.). Parte-se do pressuposto de que a verdade é única, mas que talvez o melhor seja aceitar o erro. A manutenção do pluralismo aqui é um cálculo pelo mal menor. Entre a imposição da verdade e a aceitação do erro, pode-se optar pela segunda situação como algo menos nocivo. Essa postura pode ser assumida por diferentes grupos. Pode-se imaginar, por exemplo, um grupo majoritário que aceite, por astúcia, o erro de um grupo minoritário por considerar que a perseguição pode ser mais difícil do que a simples aceitação. Um grupo dominado e minoritário poderia aceitar o erro que lhe é imposto pelo mais forte por questões de prudência, pois rebelar-se poderia lhe trazer mais danos, como a eliminação física. Aqui, tolerar é um cálculo a favor da atitude menos nociva diante da diferença alheia.

A quarta postura está baseada num personalismo moral (idem, ibid.). Aqui a verdade é única, mas está destinada a conviver com o erro. Não se acredita que a 
verdade vencerá e nem que um dia se imporá diante de todos os equívocos. Verdade e erro são como irmãs siamesas, obrigadas a conviver lado a lado. A tolerância e o pluralismo não são concessões pragmáticas, mas a aceitação do erro em nome do respeito à pessoa humana, daí o termo "personalismo moral". Segundo seus defensores, não se trata de indiferença, mas de superação da intolerância e de reprovação explícita desta, em nome do respeito à inviolabilidade das consciências individuais, como já defendia por Locke (1980) e Voltaire (2000). Essa postura faz uma separação entre razão teórica (que busca incessantemente a verdade) e razão prática (que se guia pela benevolência). Assim, a tolerância é aceitação do erro alheio em nome da benevolência com a pessoa humana, apesar do erro no qual ela se encontra.

Todas estas posturas, segundo Bobbio (op. cit.), respondem ao desafio de ser tolerante e favorável ao pluralismo sem ser cético. A tolerância e o respeito ao pluralismo sempre foram vistos como portas abertas ao ceticismo radical, como defesa de que nenhuma verdade é possível e, por isso, todas são igualmente válidas. Para Bobbio, é possível depositar suas crenças numa verdade e, ainda sim, ser tolerante e favorável ao pluralismo, de acordo com um dos quatro modelos já apresentados.

No entanto, há outra maneira de se relacionar com a verdade, que para Bobbio (2002, p. 143), é mais própria dos amantes da filosofia: “O filósofo está aberto à dúvida, está sempre em marcha; o porto a que chega é apenas a etapa de uma viagem sem fim, e é preciso estar sempre pronto para zarpar de novo". Assim, a verdade não é única ou exclusiva, mas sim múltipa e incerta. Não há verdade no singular, mas sim verdades, muitas e variadas. Aqui tampouco cabem as posturas céticas, já que não há negação da possibilidade da verdade, mas sim aceitação de que a verdade só pode existir no plural. A verdade como pluralidade também apresenta quatro posturas.

Bobbio (op. cit., p. 144) chama a primeira postura de sincrética. Nesta postura, existem várias verdades e para se entender a realidade é preciso manipular e fundir verdades de teorias diferentes e até opostas. Neste sentido, o sincrético pode ser acusado de fazer misturas impuras.

A segunda postura é chamada de eclética (ibid.). Parecida com a anterior, diferencia-se pela intenção de criar um novo sistema de verdades a partir de fragmentos de verdades. Como o sincrético, o eclético parte do princípio de que nenhum sistema de pensamento é totalmente falso ou totalmente verdadeiro. No entanto, diferente do sincretismo, não há fusão de verdades, mas há uma reorganização de teorias, uma reconciliação de diferentes doutrinas. Neste sentido, o eclético pode ser acusado de fazer combinações inadequadas.

Bobbio (op. cit.) denomina a terceira postura de historicismo. Aqui se acredita que a verdade é sempre válida a partir de um determinado tempo e lugar. As verdades 
possuem tempo histórico e circunscrição geográfica. O que é verdade hoje não será necessariamente amanhã. E o que é verdade aqui não é obrigatoriamente acolá. Para Bobbio, essa é a postura mais relativista.

A quarta postura pluralista é o personalismo (ibid.) e se assemelha à quarta postura monista. Trata-se da crença de que toda verdade é pessoal, ainda que seja comunicável a outros e transmissível entre grupos e gerações. Num personalismo pluralista, as verdades são infinitas e igualmente dignas de serem, ao menos, ouvidas. Aqui, a tolerância e o pluralismo são deveres morais em respeito à dignidade da pessoa humana, considerada como portadora de verdades, ainda que não compreendidas e aceitas por todos. A distinção desta postura em relação ao personalismo moral monista é que, naquele caso, se respeita a pessoa humana, mas não lhe confere a categoria de possuidora de verdades. Para os monistas, o respeito é pela pessoa em sua condição humana, ainda que ela esteja no erro. Para os pluralistas, o respeito é pela dignidade da pessoa humana enquanto portadora de verdades, que são sempre pessoais e igualmente válidas se colocadas num diálogo intersubjetivo.

Nas posturas sincrética, eclética e historicista, a tolerância e o pluralismo se fundamentam devido à impossibilidade de se estabelecer uma autoridade para se impor qual é a mais coerente entre as múltiplas verdades existentes. Para Bobbio (op. cit.), uma concepção pluralista de verdade não leva necessariamente à indiferença e nem à intolerância. Ao contrário, o ceticismo - enquanto ausência de verdade - é que poderia levar a essas posturas. Se, de acordo com um ceticismo exacerbado, não é possível nenhuma verdade, então, caberia o argumento de que qualquer uma poderia ser imposta como tal. Se não há critérios para ordenar aquilo que é justo ou verdadeiro, o justo e verdadeiro será aquilo que for ordenado ou imposto por um grupo devidamente forte para fazê-lo. Sem critérios para definir justiça e verdade, abre-se o flanco para que a força faça a vez dos critérios.

Bobbio abre um amplo leque para pensar a relação entre a afirmação da verdade, o valor do pluralismo e a busca da tolerância. Enfim, não é preciso ser cético para ser tolerante. Bobbio parece evitar o ceticismo por supor que este abre um espaço de argumentação para a intolerância e a indiferença.

\section{Tolerância: em defesa do pluralismo}

Cumpre retornar à disjunção feita inicialmente por Bobbio (2002), entre a tolerância baseada na problemática da verdade e a tolerância baseada na problemática da diversidade. A segunda parte desta disjunção refere-se diretamente ao preconceito e à discriminação.

Para Bobbio (op. cit.), o preconceito é somente uma opinião errônea. No entanto, trata-se de um erro mais tenaz e perigoso do que qualquer outro, pois ele alimenta 
sentimentos e representações distorcidas de um grupo em relação a outro. Assim, o preconceito é uma predisposição em creditar como verdade algo que é irrefletido. A discriminação é uma consequência direta de tal predisposição. Discriminar, enquanto ato de distinguir, não é algo necessariamente negativo, pois a discriminação de fato pode levar ao reconhecimento da diversidade, ou seja, à conclusão de que somos diferentes. Já a discriminação de valor leva a posturas etnocêntricas, que são pautadas em três fases: (1) reconhecimento da diversidade; (2) reconhecimento que dentro da diversidade pode haver relações desiguais, tais como superior e inferior; (3) uma injusta conclusão de que os superiores podem explorar os inferiores.

A novidade na argumentação de Bobbio é que até a segunda fase não se reconhece uma discriminação de cunho negativo. Para o autor, reconhecer que numa relação há superiores e inferiores não há nada de maléfico. Ele analisa, por exemplo, as relações de pai-filho e de professor-educando, considerando que os primeiros são superiores e que, numa relação tão saudável quanto esperada, não visam explorar os inferiores. A discriminação estaria na terceira fase, quando os superiores subjugam os inferiores.

A maneira de se entender as desigualdades é fundamental para a percepção de que se deva ou não lutar contra os preconceitos e as discriminações. Se as desigualdades são consideradas naturais, então serão vistas como insuperáveis. Mas, se são consideradas sociais, serão vistas como realidades superáveis. Para Bobbio (1995), o maior ou menor empenho em buscar a superação das desigualdades é o que distingue a esquerda (mais igualitária e propensa a considerar as desigualdades como realidades sociais e, por isso, elimináveis) da direita (mais inigualitária e propensa a considerar as desigualdades como realidades naturais e, por isso, insuperáveis).

Nesse sentido, Bobbio (2002; 1995) posiciona-se como um igualitarista que articula diferença e igualdade, coloca-se frontalmente contra as desigualdades e assimetrias não naturais e, ao mesmo tempo, defende as desigualdades necessárias para o desenvolvimento da vida humana, tal como as apontadas entre pai e filho ou entre professor e educando. Redefinir desigualdades e diferenças é um dos temas centrais para se entender interculturalidade e, por isso, Bobbio parece contribuir com o debate.

\section{Virtudes fracas e acordos fortes}

Talvez a mais original contribuição de Bobbio para a educação intercultural seja o fato dele oferecer uma metafísica das virtudes, elegendo a serenidade como fundamento para cidadãos democráticos e comprometidos com construção cotidiana do pluralismo. 
Bobbio (2002, p. 9) afirma que "optou por incluir" a serenidade no rol das "virtudes fracas" ou "como a mais impolítica das virtudes". Para ele, não é um desprestígio afirmar que a serenidade é uma virtude fraca, pois isso não significaria que a serenidade é a virtude dos fracassados, tampouco representaria uma fraqueza, mas sim uma fortaleza não violenta (idem). É sim uma virtude dos fracos, no sentido daqueles que não possuem poder, status ou recursos econômicos abundantes, ou seja, os fracos são cidadãos normais, iguais a tantos outros.

Para esclarecer sua concepção de virtude fraca, Bobbio (op. cit.) apresenta duas maneiras clássicas de se entender a política. Por um lado, na concepção aristotélica, política é a busca do bem comum, isto é, política como a arte do bom governo. Por outro, na concepção maquiavélica, política é a ação estratégica do estadista, ou seja, a política como a ciência dos mecanismos de conquistar e manter o poder. A concepção aristotélica pode ser entendida como virtuosa, orientada pela busca do bem comum. A concepção maquiavélica é amoral, pois não se relaciona com a reflexão sobre o que é certo ou errado, mas apenas com a disputa e a manutenção do poder. Ainda que proclamemos uma política virtuosa, bem sabemos que no jogo político a concepção predominante tende a ser outra. Se, de modo geral, a política exclui a moral, então, a serenidade é a mais impolítica das virtudes morais, porque, segundo Bobbio (op. cit.), ela é totalmente desprovida de poder.

No entanto, se a política exclui a serenidade, seria prudente se perguntar se não há outra maneira de se fazer política, outra maneira de se relacionar com o poder. Nesse sentido, é importante relativizar esta exclusão da serenidade da relação com o poder. A serenidade encontra sua força política na prática da não violência ativa, teorizada e praticada, por exemplo, por Mahatma Gandhi, Martin Luther King e Nelson Mandela. A não violência é o meio pelo qual a serenidade se converte em força e opera de modo muito distinto da violência. $\mathrm{O}$ não violento refuta a violência sem se retirar da política. Ele desmente, com seu agir, a definição maquiavélica da política como reino exclusivo da conquista e da manutenção do poder.

Ainda que Bobbio (2002) reconheça certa força na serenidade, ele reafirma que ela não é uma virtude senhorial, isto é, dos fortes, doutos, nobres ou heróis. A serenidade é típica de homens e mulheres simples, sem poder, cidadãos comuns, que vivem a história submersa, que só a podem utilizar como força através da não violência ativa, como resistência silenciosa, suportada. Assim, como Gandhi ou Luther King, os fracos podem vir a ser heróis. Mas o herói sereno e não violento. Então, é preciso entender a serenidade como virtude do ser humano sereno com ele mesmo e atitude do cidadão sereno com os outros. A serenidade é ainda mais passiva - e pacífica - quanto mais se aproxima das atitudes da tranquilidade, paciência, complacência e doçura. Serenidade é uma virtude de âmbito mais doméstico e intimista, tal como se expressa na formulação sobre estar sereno. 
No entanto, a serenidade também encontra validade na relação do cidadão sereno com os outros, pois mitigar o peso da vida requer uma relação, requer ser suporte ou dar suporte para o peso que o outro carrega. Aqui, tolerar pode sim ser suportar (dar suporte a) o peso do outro para aliviar o fardo dos problemas da vida que se compartilha. A serenidade se torna mais ativa e, por isso, mais política quando se aproxima das atitudes que visam aliviar, suavizar, mitigar a carga da coexistência e da convivência humana, tornando o mundo mais habitável para os seres humanos.

Como modo de ser em relação ao outro, a serenidade resvala o território da tolerância e do respeito pelas ideias e pelos modos de viver dos outros. No entanto, se o indivíduo sereno é tolerante e respeitoso, não é apenas isso. A tolerância é recíproca: para que exista tolerância é preciso que se esteja ao menos em dois. Uma situação de tolerância existe quando um tolera o outro. Se eu o tolero e você não me tolera, não há um estado de tolerância, mas, ao contrário, de prepotência. (Bobbio, op. cit., p. 42-43)

Mas como a serenidade e a tolerância se opõem à prepotência? Bem, esta relação fica mais clara quando o autor aprofunda sua metafísica das virtudes e define o que não é a serenidade e como ela se distingue das outras virtudes fracas. Bobbio (idem, ibid.) procura distinguir a serenidade das que lhe são semelhantes, mas que devem ser evitadas. Assim, "serenidade não é submissão". O submisso renuncia à luta por resignação ou medo. O sereno refuta a violência pela sua inutilidade enquanto meio e não à luta e aos seus fins. "Serenidade também não é humildade". O humilde é aquele que contempla a sua impotência e ainda com certa melancolia. O sereno, ao contrário, é confiante e bem disposto, pois acredita que o mundo por ele imaginado será melhor que o mundo que está obrigado a viver. "A serenidade tampouco é modéstia". O modesto é aquele que, por hipocrisia ou por falta de autoestima, avalia-se menos do que é. O sereno tem sempre uma atitude positiva em relação ao outro e em relação a si mesmo. Assim, enquanto a humildade se opõe à excessiva aprovação de si mesmo, a submissão se opõe à insubordinação; a modéstia à capacidade de se autoavaliar com honestidade, a serenidade se opõe à prepotência e à arrogância. Ainda que se assemelhem, a serenidade não é submissão, nem humildade, nem modéstia.

No entanto, a serenidade tem vínculos muito estreitos com outras virtudes fracas, tais como a simplicidade e a misericórdia. A simplicidade é a capacidade de fugir das complicações inúteis e das posições ambíguas. Ser simples é ser claro e distinto no campo das teorias e recusar a dissimulação e a ambiguidade no campo da ação política. O simples é transparente ao pensar e firme ao agir. Já a misericórdia é algo a mais, um acréscimo, um ganho para o sereno. A serenidade pode - mas não tem a obrigação de - levar à misericórdia, que é a virtude de sentir a miséria alheia no próprio coração (miserium cordis). Enfim, o sereno é simples e misericordioso, por isso foge à prepotência e acolhe a tolerância. A serenidade como recusa à prepotência "é 
a única suprema potência (...) que consiste em deixar o outro ser aquilo que é" (idem, p. 35). Segundo Bobbio (2002), a serenidade é uma virtude fraca que torna possível, entre os concidadãos, acordos fortes: a tolerância e o pluralismo. Assim, a serenidade se opõe ao abuso do poder, à prepotência e à arrogância. Daí ser a mais impolítica das virtudes.

\section{Educação intercultural: da incerteza à serenidade}

Por fim, cabe perceber algumas possibilidades de diálogo entre Popper e Bobbio para uma educação intercultural. Tentarei explicitar alguns argumentos já apresentados.

Os argumentos de Popper ajudam a ampliar os conceitos de pluralismo, verdade e tolerância para além do campo da ética e da filosofia política, já que seu pensamento traz sólidos elementos da epistemologia e duras críticas aos chamados argumentos cientificistas, tão caros a uma epistemologia multicultural (Semprini, 1999). Ainda que pouco trabalhado no âmbito dos fundamentos da educação, Popper pode ser visto como plenamente consoante com o objetivo proposto neste trabalho, já que ele cumpre o papel de ajudar a entender as correlações entre epistemologia e ética, entre verdade e valor, entre geral e particular, universalidade e diversidade. Trata-se de um autor fundamental para todos que queiram, a partir das concepções epistemológicas, relativizar a rigidez do conhecimento científico e questionar o estatuto da verdade absoluta. Tais tarefas são fundamentais para pôr em xeque um universalismo exacerbado, sem cair nas armadilhas de relativismos radicais, promovendo, assim, alguns fundamentos sólidos e racionáveis sobre uma proposta de educação intercultural, centrada no diálogo e no respeito às diferenças.

Bobbio surge neste diálogo a fim de ampliar nossas concepções sobre pluralismo e tolerância, retirando-as do campo da tradição liberal. Sem negar a influência do liberalismo político, mas sem me render a ela, optei em dar maior atenção a um pensador identificado à esquerda do pensamento político, um intelectual que compõe o campo das reflexões progressistas e emancipatórias. Nesse sentido, foi preciso dar a Bobbio maior fôlego durante o caminho percorrido, mais espaço e tempo para alguns diálogos que trouxeram novas articulações e, de certa forma, uma perspectiva mais ampla sobre os conceitos aqui analisados. Bobbio é fundamental para se argumentar a favor da verdade no plural, do pluralismo para além do ceticismo e da tolerância para além da indiferença e da falsa superioridade, permitindo, como favor de condescendência, que o outro exista em sua diversidade. Neste sentido, as distinções entre monistas e pluralistas, as relações entre preconceito e pluralismo, bem como a metafísica sobre serenidade, fazem de Bobbio um interlocutor fecundo para a fundamentação de uma educação intercultural. 
A partir de Popper e de Bobbio, busquei apresentar alguns fundamentos epistemológicos e éticos para a prática pedagógica que vem sendo chamada de intercultural (Candau, 2002; Fleury, 2003; Moreira, 2002). De Popper, a certeza de que a verdade é sempre provisória e a aposta ética na tolerância. De Bobbio, a verdade no plural e a serenidade como a capacidade de mitigar os fardos da vida. Por um lado, a epistemologia popperiana para pensar uma educação que recuse qualquer possibilidade de verdades inquestionáveis, que reconheça na cientificidade a possibilidade do erro e que afaste de nossa maneira de pensar os dogmatismos intolerantes, as verdades prontas e as certezas supostamente objetivas, imparciais e neutras. Por outro lado, a filosofia política bobbiana - marcadamente emancipatória - para desenhar uma educação como prática social formadora de homens e mulheres respeitosos da diversidade, porque cientes da necessidade de estruturas mínimas para a garantia de uma igualdade que respeite, de fato, o pluralismo entre todos e todas, superando preconceitos, discriminações e posturas etnocêntricas.

Sem dúvida, a interlocução nevrálgica entre os dois autores é a articulação entre temas epistemológicos e éticos, superando a falsa dicotomia entre definição de verdade e concepções de justiça e de bem. Nestes termos, uma proposta de educação intercultural pode gestar práticas nas quais há valor em virtudes fracas, incertas e plurais, pois a prepotência é a força da intolerância e da mesmice totalitária que tanto precisamos superar no campo educacional.

\section{Referências}

ARTIGAS, M. Lógica y ética en Karl Popper. Pamplona: Eunsa, 1998.

BOBBIO, N. Direita e esquerda: razões e significações de uma distinção política. São Paulo: UNESP, 1995.

BOBBIO, N. Elogio da serenidade e outros escritos morais. São Paulo: UnesP, 2002.

CANDAU, V.M. (Org.). Sociedade, educação e cultura(s): questões e propostas. Petrópolis: Vozes, 2002.

CANDAU, V.M. (Org.). Educação intercultural e cotidiano escolar. Rio de Janeiro: 7 Letras, 2006.

CANDAU, V.M. Multiculturalismo e educação: desafios para a prática pedagógica. In: Moreira, A.F.; CandaU, V.M. Multiculturalismo: diferenças culturais e práticas pedagógicas. Petrópolis: Vozes, 2008. p. 13-37.

CARDOSO, C.M. Tolerância e seus limites: um olhar latino-americano sobre diversidade e desigualdade. São Paulo: UnesP, 2003. 
FISCHMANN, R. Educação, direitos humanos, tolerância e paz. Paidéia, Ribeirão Preto, v. 11, n. 20, p. 67-77, 2001.

FISCHMANN, R. Injustiça, autonomia moral e organização escolar: análise exploratória de relações. Paidéia, Ribeirão Preto, v. 17, n. 38, p. 321-330, 2007.

FISCHMANN, R. Ciência, tolerância e Estado laico. Ciência E Cultura, São Paulo, n. 60, p. 42-50, 2008.

FLEURY, R. Intercultura e educação. Revista Brasileira de Educação, Rio de Janeiro, n. 23, p. 16-35, 2003.

FLEURY, R. Políticas da diferença: para além dos estereótipos na prática educacional. Educação E Sociedade, Campinas, v. 27, n. 95, p. 495-520, 2006.

GRUPIONI, L.D.B.; VIDAL, L.B.; FISCHMANN, R. (Org.). Povos indígenas e tolerância: construindo práticas de respeito e solidariedade. São Paulo: EDUsP, 2001.

KUNSCH, M.M.K.; FISCHMANN, R. (Org.). Mídia e tolerância: a ciência construindo caminhos de liberdade. São Paulo: Edusp, 2001.

LOCKE, J. Carta acerca da tolerância. São Paulo: Abril Cultural, 1980.

MOREIRA, A.F. Multiculturalismo, currículo e formação de professores. In: MoreIRA, A.F. (Org.). Currículo: políticas e práticas. Campinas: Papirus, 1999. p. 59-79.

MOREIRA, A.F. Currículo, diferença cultural e diálogo. Educação E Sociedade, Campinas, v. 23, n. 79, p. 15-38, 2002.

PLASTINO, C.A. O primado da afetividade: a crítica freudiana ao paradigma moderno. Rio de Janeiro: Relume-Dumará, 2001.

POPPER, K. A lógica da pesquisa científica. São Paulo: Cultrix, 1972.

POPPER, K. A sociedade aberta e seus inimigos. Belo Horizonte: Itatiaia, 1987a.

POPPER, K. Toleration and intellectual responsibility. In: MEndus, S.; EdwARds, D. (Ed.). On toleration. New York: Oxford University, 1987b. p. 17-34.

POPPER, K. En busca de un mundo mejor. Barcelona: Paidós, 1994.

SEMPRINI, A. Multiculturalismo. Bauru: EDUSC, 1999.

SILVA, T.T. (Org.). Identidade e diferença: a perspectiva dos estudos culturais. Petrópolis: Vozes, 2000a.

SILVA, T.T. Currículo, universalismo e relativismo: uma discussão com Jean-Claude Forquin. Educação \& Sociedade, Campinas, v. 21, n. 73, p. 71-78, 2000 b. 
VOLTAIRE, F.M.A. Tratado sobre a tolerância. São Paulo: Martins Fontes, 2000.

WALZER, M. Da tolerância. São Paulo: Martins Fontes, 1999.

Recebido em 24 de julho de 2009.

Aprovado em 10 de agosto de 2010. 